\title{
Satellites aim to shake up quake predictions
}

\section{Tony Reichhardt, Washington}

The controversial idea that earthquakes can be predicted by monitoring tiny fluctuations in Earth's magnetic field is to be tested by two new satellites.

Although many seismologists see little merit in the idea, NASA and the US Air Force are together contributing about $\$ 1$ million to provide data analysis and ground instrumentation to support experiments with the first satellite, the privately funded QuakeSat. Built by QuakeFinder of Palo Alto, California, the craft is now returning data from orbit after its 30 June launch. A second more expensive and ambitious satellite, funded by the CNES, France's national space agency, will follow next April.

Both craft are designed to search for small variations in Earth's magnetic field, which some scientists believe precede earthquakes. According to their theories, extremely lowfrequency magnetic fluctuations are produced by compression of crystalline rocks or the movement of water in fault zones before a quake. Such fluctuations could potentially be detected from an orbiting satellite.

The idea of using magnetic activity to predict earthquakes is not entirely without precedent. Antony Fraser-Smith, a geophysicist at Stanford University in California who is among those who will receive NASA funds to work on QuakeSat data, reported elevated ground-based magnetic signals several days before the 1989 Loma Prieta earthquake, which damaged San Francisco and other cities in California (A. C. Fraser-Smith et al. Geophys. Res. Lett. 17, 1465-1468; 1990). Most Earth scientists consider these results to be interesting but inconclusive.

There is also tentative evidence that such fluctuations could be detected from space.

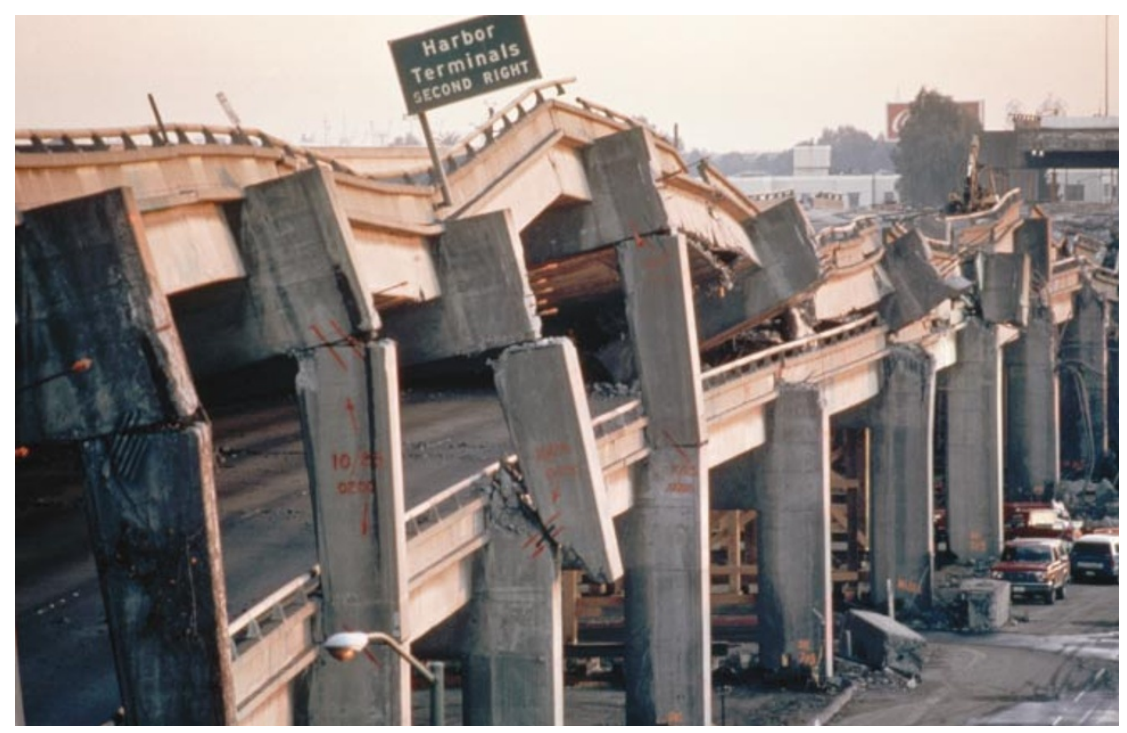

Satellite studies will look at the idea that magnetic signals preceded the 1989 Loma Prieta quake.

Russia's Cosmos-1809, for example, managed to record signals from a 1989 earthquake in Armenia. Although some other satellites have turned up no such evidence, the subject intrigues geophysicists.

QuakeSat, built in collaboration with Stanford's Space Systems Development Laboratory, will now test these ideas. The satellite, which will collect data on magnetic-field strength from orbit for about six months, will have greater coverage than groundbased magnetometers - which are QuakeFinder's main product.

The company's president, Marijean Seelbach, admits that "the jury's still out" on whether the device can predict earthquakes. Stephen Park, a geophysicist at the University of California, Riverside, is typical of those who doubt that it can. Magnetic fields during the main shock of an earthquake generally measure billionths of a tesla at the fault line, he points out. Precursor fluctuations are likely to be lower, and would lose energy as they travel to the satellite. Seelbach agrees that measuring such tiny signals is a daunting task, but says that QuakeSat will be sensitive to trillionths of a tesla.

NASA is also "agnostic" about whether the satellites will prove useful, says John LaBrecque, manager of the agency's Solid Earth and Natural Hazards research programme in Washington. He admits that NASA would have had difficultybeing the sole funder for such a controversial project, but says he feels the agency is justified in making a contribution to a private scheme.

\section{US researchers fear job losses from privatization drive}

\section{Rex Dalton, San Diego}

US scientists have reacted anxiously to a government plan to contract out federal scientific projects, citing fears that the scheme could damage research. The plan met stiff opposition in Congress earlier this month, but the Bush administration wants to implement it before the November 2004 presidential election.

The administration's plan involves contracting out about 425,000 federal jobs, which may include hundreds of researchers. Under the scheme, private firms with scientific staff might perform research that is now conducted by government scientists. Administration officials say that privatizing jobs will save money and increase efficiency.
The scheme hit problems on 17 July, when the House of Representatives voted to block plans to privatize two National Park Service regional archaeology centres, involving 100 staff. Researchers at the Midwest Archeological Center in Lincoln, Nebraska, and the Southeast Archeological Center in Tallahassee, Florida, have been carrying out cultural studies on public and private lands for more than $\mathbf{3 0}$ years.

But further disputes are expected in the coming weeks, as congressional hearings for the 2004 financial-year budget discuss privatization in other agencies, such as the National Institutes of Health (NIH) and the Environmental Protection Agency (EPA). One union official at the EPA says he fears that 150 jobs in his 1,000-member chapter could be privatized. The NIH is already studying how to outsource almost 1,000 jobs in the 2004 fiscal year.

Critics of the plan say that staff whose positions are privatized could lose their jobs if they are not re-employed by the private firm that takes over. Others add that private companies could be more willing to bow to political pressure over controversial research. "When you replace government scientists with private ones, the latter are more likely to pull their punches, and not raise or address sensitive issues," says Jeff Ruch of Public Employees for Environmental Responsibility, a Washington-based pressure group that promotes government accountability. 